\title{
Disperse Systems in Gases: Dust, Smoke and Fog
}

$\mathrm{T}$ HE Faraday Society held one of its biannual general discussions in the Chemistry Department of the University of Leeds on April 20-22. The subject of the discussion in this instance was "Disperse Systems in Gases : Dust, Smoke and Fog". The meeting was held under the joint chairmanship of Sir Robert Robertson and Prof. F. G. Donnan, owing to the illness of the Society's president, Mr. William Rintoul.

Among the distinguished foreign and overseas guests of the Society attending the discussion were : Prof. J. Firket (Liège), Dr. E. Hiedemann (Cologne), Prof. H. Köhler (Uppsala), Dr. and Mrs. R. Meldau (Berlin-Charlottenburg), Dr. J. L. van der Minne (Amsterdam), Prof. H. Remy (Hamburg), Dr. P. Schuftan (Munich), Dr. H. Schmeel (Darmstadt), Dr. P. Siedler (Frankfort-on-Main).

The discussion was divided into two parts, the first dealing with the general properties and behaviour of dispersed systems, whilst the second was the industrial aspect of such systems in air and gases. In addition, the discussions on Part I were subdivided into those dealing with systems of nonvolatile particles, such as smokes and dusts, and systems of aqueous and other volatile particles, such as mists, clouds and fogs.

In an introductory paper to the first part of the discussion, Prof. R. Whytlaw-Gray of the University of Leeds gave a comprehensive summary of modern knowledge of smokes. He pointed out that one of the most fundamental properties of any dispersed system in a gas was its power of spontaneous coagulation. He showed that when dealing with ideal smokes in the laboratory, the decrease of number of particles with time was in conformity with the theoretical equations of von Smoluchowski. Dr. W. R. Harper (Bristol) criticised the derivation of these equations and submitted an alternative method of treatment, which, however, led to the same final formulæ. One point of great interest arose out of the discussion on coagulation which followed, this being the extreme lack of information regarding the initial formation of particles from volatilised sub. stances, and whether there is in fact a primary particle (that is, a homogeneous particle of minimum size as distinct from larger particles consisting of loose aggregates) or not. The microscopic examination of smokes of crystalline substances and the work of Prof. Fuchs (Moscow) on sulphuric acid droplets tends to support the former view. The effect of the reduction of pressure in increasing the rate of coagulation was also discussed.

Two other phenomena exhibited by dispersed systems were also brought before the meeting. The first was the enforced and very rapid coagulation of particulate matter by means of sound waves of supersonic frequencies. In this connexion, Dr. Hiedemann gave a description of his inspiring and extremely comprehensive experimental researches, whilst Prof. E. N. da C. Andrade put forward a theoretical explanation of the phenomena. In the somewhat lively discussion which followed, the economic possibilities of using this method in industry were treated. The other phenomenon was that seen so frequently above radiators, that is, the deposition of particulate matter on cold surfaces, and the reverse effect of a dust-free space around hot bodies. Mr. H. H. Watson (Porton) gave an account of an experimental investigation of this effect, which was followed with an attempted theoretical explanation by Dr. W. Cawood, based on the assym. metrical bombardment of the particles in a temperature gradient by the gas molecules.

Mr. H. L. Green (Porton) gave an account of an investigation of certain harmful commercial dusts. After describing a method of measuring the particle size distribution, he showed that in all such dusts the range of size was about $0 \cdot 2 \mu-2 \mu$ in diameter, and that the number distribution appeared to be quite random. He pointed out the importance of such measurements in industry due to the probability that certain sizes of particles are more toxic than others.

The next part of the meeting, that is, the part dealing with volatile particles, somewhat naturally resolved itself mainly into a discussion on atmospheric conditions. Dr. G. M. B. Dobson (Oxford) presented the introductory paper, and whilst giving a résumé of our present knowledge of these systems, at the same time stressed the points about which very little is known, such as the distribution of fogs and particulate matter around towns and the effect of dispersoids in cutting off sunlight and daylight.

That in country air the nuclei upon which fogs and mists condense consist mainly of very fine particles of sea salts has been shown by J. H. Coste and H. L. Wright. At this meeting, however, Mr. Coste showed that, in towns, in addition to such nuclei there are nuclei of sulphuric acid droplets, and described how the sulphuric acid content of the air might be determined. He also put forward experimental evidence in support of the view that droplets of nitrous acid are formed by the various combustion processes in a city, which also act as hygroscopic nuclei for the formation of fogs. Prof. Hilding Köhler gave an account of his researches, mainly carried out on the slopes of the Haldde, which also show that the centres of condensation in country air mainly consist of sodium chloride. In addition, he gave a very complete account of the thermodynamics of condensation upon such nuclei. Similar considerations were also shown by Dr. C. F. Goodeve (London) to apply to the old problem of the behaviour of sulphuric acid mist in air of different water vapour concentrations. The determination of the actual mass and size of these atmospheric nuclei was described by Prof. J. J. Nolan (Dublin), who showed that they were identical with the Langevin ions, and the average radius was about $2-3 \times 10^{-6} \mathrm{~cm}$. Prof. J. C. Philip then gave a description of the part played by certain hygroscopic nuclei of ammonium chloride in the formation of fog.

As a rather disturbing climax to this part of the discussion, during which so many of the properties of the nuclei necessary to form a fog had been investigated and described, Prof. J. Firket gave an account of those terrible days during December 1930 when sixty-three people died and several hundred were affected as a result of a dense fog along the Meuse Valley. Prof. Firket described how he and his collaborators proved that the toxic material in 
the fog was almost certainly sulphur dioxide and its oxidation product sulphuric acid (the latter being the more poisonous and the actual cause of the casualties), formed in the combustion of coal. It is of interest to note that one fifth of the sulphurous products had their origin in the domestic fireplace. Prof. Firket also said that, given the same exceptional atmospheric conditions, undoubtedly the accidents would occur again unless special plants were installed to absorb the sulphurous fumes from the flue gases of industrial furnaces.

The section of the discussion dealing with the industrial aspects of dispersed systems was opened by Dr. R. Lessing (London), who gave a comprehensive account of the dusts, smokes and fogs formed in various industrial processes, and then described how the flue gas problem had been successfully overcome in Britain. He showed that in the burning of coal, by means of efficiently designed furnaces, the black smoke of unburned carbonaceous matter, once so common, had practically disappeared, so that only a dust of siliceous ash was left in the flue gases. However efficient the furnace, the sulphur oxides are unchanged, and consequently in modern practice the flue gases must be washed by an alkaline solution in order to eradicate them. Mr. G. Nonhebel (Durham) described how the Howden-I.C.I. flue gas scrubber carried out this process. The essential point of the system appears to be the strict control of the $p \mathrm{H}$ of the alkaline scrubbing water in order to obviate the copious encrustation of calcium sulphate in the scrubbers.

Apart from the problem of eleansing flue gases in order to prevent air pollution, there is also the problem of precipitating dusts and smokes in such a way that they can be collected. The most widely used method is the Lodge-Cottrell process of electrical precipitation. In this connexion, Dr. R. W. Lunt
(London) discussed the electrical efficiency of the ionisation in such processes. He showed that the ordinary laws do not hold in the corona discharge and that by applying more refined theoretical methods it can be proved that the efficiency is far below the maximum.

A paper was presented by Dr. J. S. Owens (London) entitled "Twenty-five Years of Progress in Smoke Abatement". The study of the various observations taken by Dr. Owens in different parts of Britain shows that the choice of the word 'progress' is unfortunate, as the pollution in certain areas is worse than it was twenty-five years ago. Dr. R. Meldau then described the extreme difficulties of forecasting where dust should distribute itself in and around cities owing to the microvariations of the atmospheric conditions. Mr. Bosanquet dealt with the theoretical aspects of the same problem, in particular, the spread of pollution from chimneys, taking into account the various phenomena of eddy diffusion. $\mathrm{He}$ showed that at points close to the chimney the concentration at ground-level is small and that it reaches a maximum at a distance of the order of ten times the chimney height.

Prof. D. Brunt then described in a general way the dissipation of fogs in open spaces such as aerodromes. He took the view that this is now mainly a problem for the engineers. Indeed, one of the results of the discussion was to show that the abatement of atmo. spheric pollution is now a technical and economio rather than a scientific problem.

In conclusion, the Faradoy Society is to be congratulated upon organising an extremely interesting and useful discussion, which should have important consequences in this field of scientific study $\rightarrow$ a field moreover which has a direct bearing upon the improvement of the living and working conditions of people in industrial cities.

\section{International Conference on Timber Utilisation}

\begin{abstract}
CHANGES in industry and in housing which $(1$ have taken place on the Continent since the Great War have altered the incidence of demand for wood, more especially in the small material which formerly was used for frewood or turned into charcoal. Faced with a big unsaleable surplus of such material, forest owners have tried to find new outlets for it, and progress in this direction may be summarised as the use of scientific control in methods of turning wood into a homogeneous product suited to mechanised mass-production conditions of manufacture.

Of the papers read at the Second International Conference on Timber Utilisation recently held in London, the bulk referred more to the disposal of the wood in the round from the forest than to the actual processes of manufacture, and those which referred to uses of wood other than that of a construction material dealt only with very general aspects of the case which have been known for many years.

Dr. von Monroy classified these other uses into wood as a source of energy (other than that of direct combustion, of course), as a textile, a food-stuff and a raw material in chemistry. He himself demonstrated part of the source of energy use by coming
\end{abstract}

to the Conference in a motor-car driven by producer gas, and spoke of the recent hydrogenation processes evolved for converting wood gas into light and heavy fuel oils.

Dr. Friedrich Bergius in his paper on "Wood, a New Raw Material" dealt with the subject of the preparation of 'wood sugar' and its derivatives, alcohol, glycerol, etc., where improved technique has, he claims, attained the conversion of the whole of the wood substance except the lignin, or roughly two thirds of the original wood. This, he said, results in the possibilities of obtaining from one acre of woodland as much food-stuff as from one acre of arable land and with less labour in cultivation.

Prof. E. Hagglund, following Dr. Bergius, referred to the textile aspect, as concerned with artificial silk and wood pulp. Here, again, progress has lain in improvements in manufacturing methods leading to a reduction in the price of producing viscose and to the use of sulphate pulp in the cuprammonium process, which until then had been restricted to cotton linters. He foreshadowed the use of broad. leaved species in the manufacture of high grade pulp, from which they have hitherto been excluded on account of the shortness of their fibre. 